\title{
Topical Instillation of Resveratrol Preconditioned Wharton's Jelly Mesenchymal Stem Cell Secretome Preserves Ocular Surface in Experimental Model of Severe Dry Eye Disease
}

Diandra Astaridewi ${ }^{1}$, Evelyn Komaratih ${ }^{1}$, Yuyun Rindiastuti ${ }^{1}$, Yohanes Widodo Wirohadidjojo ${ }^{2}$, Djoko Legowo ${ }^{3}$, Ni Made Inten Lestari ${ }^{1}$, Diandra Astari Dewi ${ }^{1}$, I. Made Satya ${ }^{1}$, Fedik A. Rantam ${ }^{4}$, Cita R. S. Prakoeswa ${ }^{5 *}$

${ }^{1}$ Department of Ophthalmology, Faculty of Medicine, Universitas Airlangga, Dr. Soetomo General Academic Hospital, Surabaya, Indonesia; ${ }^{2}$ Department of Dermatovenerology, Faculty of Medicine, Universitas Gadjah Mada, Dr. Sardjito General Academic Hospital, Radioputro Building, Yogyakarta, Indonesia; ${ }^{3}$ Department of Pathology Anatomy, Faculty of Veterinary Medicine, Universitas Airlangga, Kampus C Mulyorejo, Surabaya, Indonesia; ${ }^{4}$ Stem Cell Research and Development Center, Universitas Airlangga, Tropical Disease Center Building, Kampus C Mulyorejo, Surabaya, Indonesia; ${ }^{5}$ Department of Dermatovenerology, Faculty of Medicine, Universitas Airlangga, Dr. Soetomo General Academic Hospital, Surabaya, Indonesia

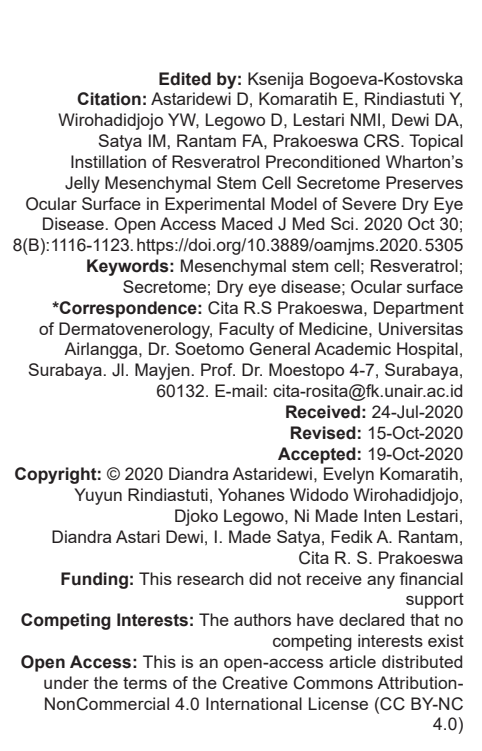

\begin{abstract}
BACKGROUND: Secretome derived from Wharton's jelly mesenchymal stem cells (WJ-MSC) has a beneficial effect for ocular surface regeneration; however, the high amount of vascular endothelial growth factor (VEGF) remains a challenge for its application.

AIM: The aim of the study was to investigate the effect of resveratrol (RV) (VEGF reducing agent) preconditioned WJ-MSC secretome in Concanavalin A-induced severe dry eye model.

METHODS: Pre- and post-experimental study composed of topical instillation of WJ-MSC secretome group, balanced salt solution control group, and normal control group. Tear production, tear break-up time (TBUT), corneal fluorescein dye staining, VEGF level in aqueous tear, goblet cell density, and inflammatory cells in the ocular surface were analyzed.

RESULTS: Topical instillation of RV preconditioned WJ-MSC secretome successfully improved tear film production $(p=0.008)$ and TBUT $(p=0.008)$, promoted goblet cell restoration $(p=0.023)$ and reduced corneal fluorescein staining $(p=0.003)$, while inhibited infiltration of inflammatory cells $(p=0.01)$ and secretion of VEGF in aqueous tear $(p=0.003)$.

CONCLUSION: Topical instillation of RV preconditioned WJ-MSC secretome has great potential as cell-free based therapy to preserve ocular surface in an experimental model of severe Dry eye disease.
\end{abstract}

\section{Introduction}

Dry eye disease (DED) is an important public health problem that could hinder the performance of daily living activities, and therefore decreases the quality of life [1], [2] The inflammatory process in accordance with downregulation of growth factors such as epidermal growth factor (EGF), hepatocyte growth factor (HGF), and keratinocyte growth factor, while increasing of vascular endothelial growth factor (VEGF) leads to ocular surface damage in DED. VEGF-A, member of the cysteine superfamily plays a key role in corneal neovascularization [3], [4], [5], [6]. The mainstay therapy for DED is the application of artificial tears and topical anti-inflammatory or immunosuppressant that provides additional lubrication for the ocular surface and improves the symptoms of chronic inflammation. However, limited results and adverse ocular effects have been reported. In recent years, regenerative therapy has emerged a new strategy that promises an improvement in the management of DED [1], [2], [7].

Wharton's jelly mesenchymal stem cells (WJ-MSC) are multipotent stem cells with the ability to differentiate into many mesoderm cell lineages. Investigation of MSC to treat immune-mediated disease has gained encouraging results [1], [2]. MSC transplantation has raised exciting expectations in 
the treatment of DED and regeneration of the ocular surface damage [1], [3]. Immunomodulation as a basic therapeutic effect of stem cells is accomplished by the secreted bioactive factors that act as autocrine and paracrine effects in the term of cell secretome [8], [9]. The remain question in the management of dry eye using stem cells product is to elaborate the tolerable and effective MSC conditioned eye drop with low VEGF as the main of pro-angiogenic factor. Several attempts have been made to stimulate specific growth factors released by MSCs, such as manipulating culture with hypoxic condition, 3D culture system, and small molecule supplementation [1], [2]. Resveratrol $(\mathrm{RV})$ is a small molecule phytoalexin agent, with a significant effect in reducing VEGF secretion in various cell lines [5], [6]. In this study, we adopted strategy by preconditioning MSC with RV to promote the secretion of EGF and HGF, while reducing VEGF secretion as the key growth factors for cell-free base therapy in DED. This study aimed to investigate the effects of topical instillation of RV preconditioned WJ-MSC secretome in the preservation of ocular surface in Concanavalin A-induced severe DED model.

\section{Materials and Methods}

\section{Materials}

Reagents included balanced salt solution (BSS) and Concanavalin A (ConA) from Sigma (St Louis, Missouri, USA). EGF, HGF, and VEGF-A enzyme-linked immunosorbent assay (ELISA) kit from Bioassay Technology Laboratory (Shanghai, China), hematoxylin-eosin (HE) from Merck (Massachusetts, USA), phycoerythrin (PE) conjugated antibodies against CD44, CD105, and CD45 and FACS Attune Acoustic Focusing Cytometer software from BD bioscience (New Jersey, USA). For the clinical experiment, we used Hamilton syringe with a 33-gauge needle (Hamilton, Reno, NV), Schirmer filter paper (Eye care products, India), fluorescein paper strip (Eye care products, India), portable slit lamp (KOWA SL-17, UK), light microscope from NIKON H600L with DS Fi32 300 megapixel camera, and Canon digital camera (A2500, 16 Megapixel).

\section{Methods}

Stem cell isolation and secretome production

Wharton's jelly MSC was isolated from a single donor of umbilical cord, obtained from a healthy baby through caesarian section using the aseptic technique. The baby's umbilical cord of length $3 \mathrm{~cm}$ was collected after the mother's consent (ethical clearance number: 1293/KEPK/VII/2019). Cells were isolated using the mixed enzymatic-explant method [10]. Cell pellets were suspended in a culture medium composed of $\alpha-M E M$, $1 \%$ penicillin-streptomycin, $1 \%$ amphotericin $\mathrm{B}, 1 \%$ non-essential amino acid (NEAA), 5\% fetal bovine serum (FBS), and $5 \mathrm{ng} / \mathrm{mL}$ basic fibroblast growth factor, then stored in an incubator at $37^{\circ} \mathrm{C}$ and $5 \% \mathrm{CO}_{2}$. Cell characterization was conducted using FACS flow cytometry using CD44, CD105, and CD45 antibody. A total amount of $5 \times 10^{3}$ cells/well of WJ-MSC at passage 4 was cultured in 96 multiwall plate with culture media for $24 \mathrm{~h}$ to obtain $70 \%$ confluency. The cells treated for $24 \mathrm{~h}$ using media composed of $\alpha-M E M, 1 \%$ penicillinstreptomycin, 1\% amphotericin B, 1\% NEAA, and $2 \%$ FBS supplemented with $0.1 \mu \mathrm{M}$ RV after $70 \%$ of confluency was reached. The level of VEGF, EGF, and HGF in cell supernatant was measured using ELISA according to Bioassay Technology Laboratory protocol (Shanghai, China). The secretome was collected then filtered using 0.45 um Millipore filter, the osmolarity and acidity were adjusted for 270-300 mOsm/L and 7.27.5 , respectively. The secretome was packaged into a single-dose application in a sterile Eppendorf tube at $50 \mu \mathrm{l}$ volume to avoid contamination and maintain the stability. The secretome was stored at $-20^{\circ} \mathrm{C}$ until further application.

\section{Animal model and treatment}

All experiments were conducted with approval from the Animal Care and Use Committee, Faculty of Veterinary Medicine Universitas Airlangga (2.KE.099.05.2019). Three-month-old male New Zealand White Rabbits were purchased from The National Agency of Drug and Food Control of Republic Indonesia and maintained in a specific pathogen-free environment. The experiment was divided into three groups, including topical instillation of RV preconditioned WJ-MSC secretome group, BSS control group, and normal control group. The experiments were repeated in three independent experiments, and each of them included at least five rabbits per group. A total of 15 male rabbits with bodyweight $2.5-3 \mathrm{~kg}$ were randomly assigned to one of three groups with five rabbits in each group. To create a severe DED model, we conducted resection of half parts of the inferior lacrimal gland and intraglandular injection of $300 \mu \mathrm{g}$ ConA in $20 \mu \mathrm{L}$ PBS using Hamilton syringe with a 33-gauge needle. Topical instillation of MSC secretome was administered every $8 \mathrm{~h}$ for 7 days in the treatment group as well as topical instillation of BSS in BSS control group. No lacrimal gland manipulation and treatment were given in the normal control group.

\section{Measurement of tear production using Schirmer tear test (STT)}

Aqueous tear production was measured with standardized Whatman Schirmer paper. The paper was 
inserted in the lateral cantus for $60 \mathrm{~s}$ and the length of wetting paper was measured in millimeters.

\section{Tear break-up time (TBUT)}

TBUT was determined by applying sodium fluorescein test strips onto the inferior conjunctival fornix, following which, the eyelids were opened and closed manually to distribute the fluorescein within the tear film. The eye was manually opened and the time between blink and appearance of first black spot in the pre-corneal tear film was observed under a portable slit lamp with cobalt blue illumination and recorded in second.

\section{Corneal fluorescein dye staining}

To evaluate the corneal epithelial integrity, corneal staining was performed by pre-wetted sodium fluorescein test strips onto the inferior lateral conjunctival sac. The corneal surface was observed in the portable slit lamp, cobalt blue light, and zoom 16 times. Photographs were taken with digital camera (Canon, A2500, 16 Megapixel), each image was coded to match pre- and post-treatment. The area of fluorescein staining was evaluated using Image $\mathrm{J}$ (v1.48) in 3 times by independent observer for the group assignment.

\section{Histopathology}

Enucleation procedure was performed to get the whole eyeball. The eyeball was stored in formalin and sliced in $4 \mu \mathrm{m}$ and subjected to H\&E staining. The histopathological section then examined in five different visual fields using Nikon H600L microscope under $\times 400$ magnification. Goblet cell density presented as mean of goblet cell density, the infiltration of the inflammatory cell was counted using Cell Count Nikon Image Systems and presented as mean of inflammatory cell.

\section{Measurement of VEGF-A level in the tear}

film

VEGF measurement was conducted to determine the angiogenic factor that was contained in aqueous tear result from the inflammatory condition of the ocular surface. VEGF was measured using VEGF-A ELISA kit according to the protocol from Bioassay Technology Laboratory, Shanghai, China. Briefly, $20 \mu \mathrm{L}$ of aqueous tear was collected using $20 \mu \mathrm{L}$ micropipette in lateral cantus region of the eye. A total amount of $20 \mu \mathrm{l}$ sample was placed into ELISA well plate, with biotinylated antibody and streptavidin HRP added and incubated at $37^{\circ} \mathrm{C}$ for $60 \mathrm{~min}$. Sample was washed $\times 3$ with buffer, with solution $A$ and $B$ added and incubated at $37^{\circ} \mathrm{C}$ for $10 \mathrm{~min}$. Finally, stop solution was added and the plate was read immediately using a microplate reader at an absorbance of $450 \mathrm{~nm}$.

\section{Statistical analysis}

Statistical analyses regarding STT and TBUT data were Kruskal-Wallis test and Mann-Whitney posthoc test. The level of VEGF-A in aqueous tear, area of fluorescein dye staining, goblet cell density, and inflammatory cells was analyzed using one way ANOVA and Games-Howell post-hoc test. All of the results considered to be significant if $p<0.05$.

\section{Results}

\section{Stem cell secretome}

We were successfully cultured cell population that fulfilled MSC criteria such as fibroblast-like formation, adhere to culture dish, positive for CD44 and CD105, but negative for CD45 with flow cytometry analysis as depicted in Figure 1. RV at $0.1 \mu \mathrm{M}$ promotes HGF secretion (250 $\pm 8 \mathrm{pg} / \mathrm{mL})$ and EGF secretion $(76.67 \pm 15.67 \mathrm{pg} / \mathrm{mL})$, while the VEGF secretion was quite low $(65 \pm 5.02 \mathrm{pg} / \mathrm{mL})$.

\section{Topical instillation of RV preconditioned} WJ-MSC secretome increased tear production

The tear production was significantly increased after topical instillation of WJ-MSC secretome group (Table 1 and Figure 2). In addition, topical instillation of WJ-MSC secretome significantly improved TBUT score, indicating recovery of tear film stability (Table 1).

Table 1: Topical instillation of RV preconditioned WJ-MSC secretome improved tear production and TBUT

\begin{tabular}{|c|c|c|c|c|c|c|}
\hline \multirow{3}{*}{$\begin{array}{l}\text { Time } \\
\text { point }\end{array}$} & \multicolumn{6}{|l|}{ Group } \\
\hline & \multicolumn{2}{|c|}{ WJ-MSC secretome } & \multicolumn{2}{|l|}{ BSS control } & \multicolumn{2}{|c|}{ Normal control } \\
\hline & $\overline{\mathrm{STT}}(\mathrm{mm})$ & TBUT (s) & $\overline{\mathrm{STT}}(\mathrm{mm})$ & TBUT (s) & $\mathrm{STT}(\mathrm{mm})$ & TBUT (s) \\
\hline Day-0 & $4.10 \pm 0.22$ & $5.4 \pm 0.54$ & $4.0 \pm 0.0$ & $5.4 \pm 0.57$ & $21.2 \pm 0.83$ & $16.4 \pm 0.54$ \\
\hline Day-7 & $12.6 \pm 0.89^{\mathrm{a}, \mathrm{b}}$ & $10.4 \pm 1.14^{\mathrm{a}, \mathrm{b}}$ & $4.8 \pm 0.83^{b}$ & $5.6 \pm 0.54^{b}$ & $20.6 \pm 0.89$ & $17.0 \pm 0.58$ \\
\hline
\end{tabular}

test, TBUT: Tear break-up time.

\section{Topical instillation of RV preconditioned} WJ-MSC secretome promoted regeneration of corneal epithelial cell

Before topical instillation of MSC secretome, all eyes had the same baseline profile of ocular surface conditions. After topical instillation of WJ-MSC secretome, ocular surface improvement in the treatment group was observed by day 7 . This was shown by reduction into mild ciliary hyperemia without any corneal opacity and decreased of fluorescein dye staining area as the sign of corneal epithelial defect compare to the BSS control group (Figure 3 and Table 2). 

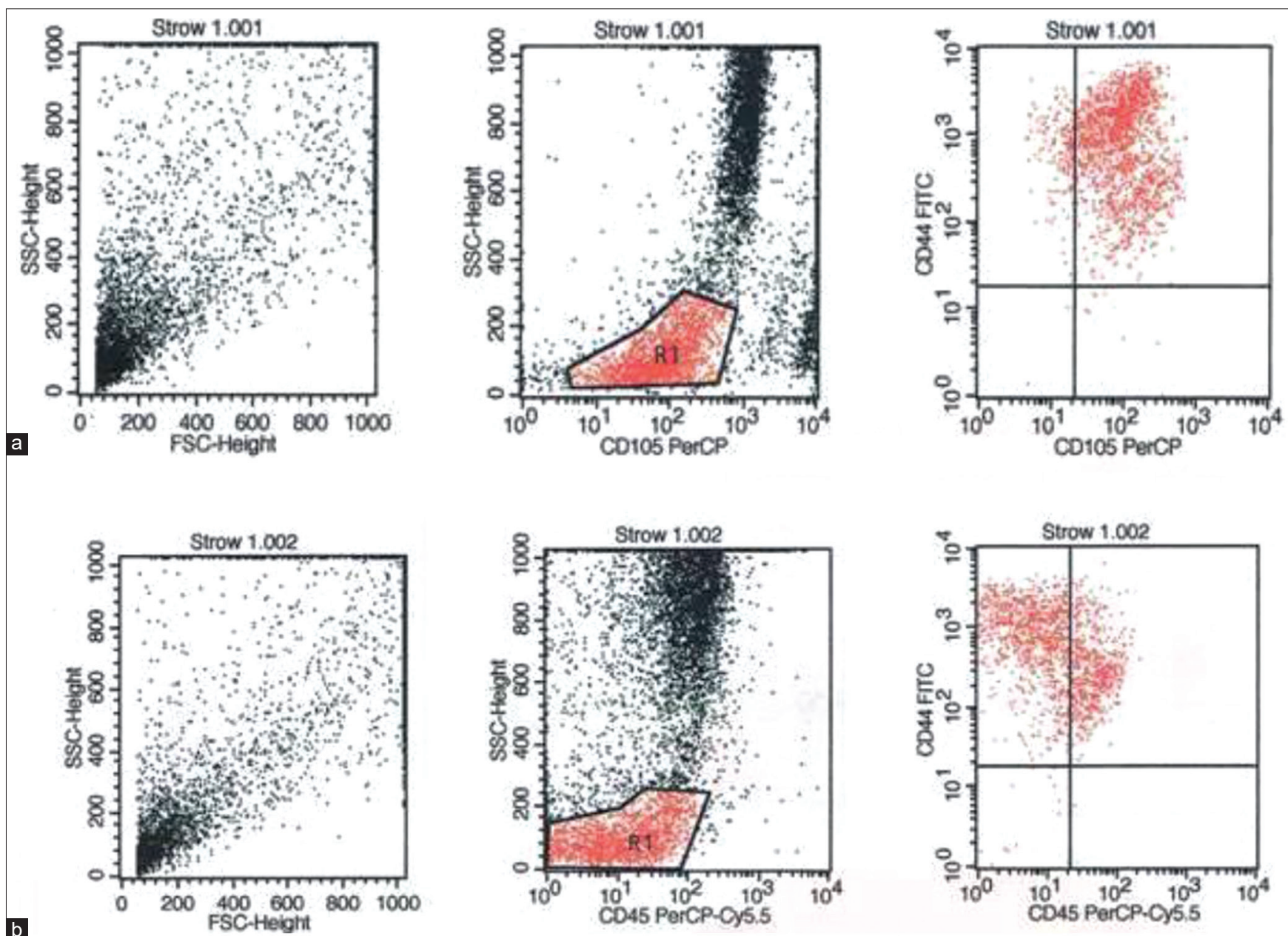

Figure 1: Identification of CD44, CD105, CD45 cell population using flow cytometry, (a) cell positive for CD44 and CD105 (88.94-89.01\%), (b) cell positive for $C D 45$ and negative for $C D 44$ (0.08\%)
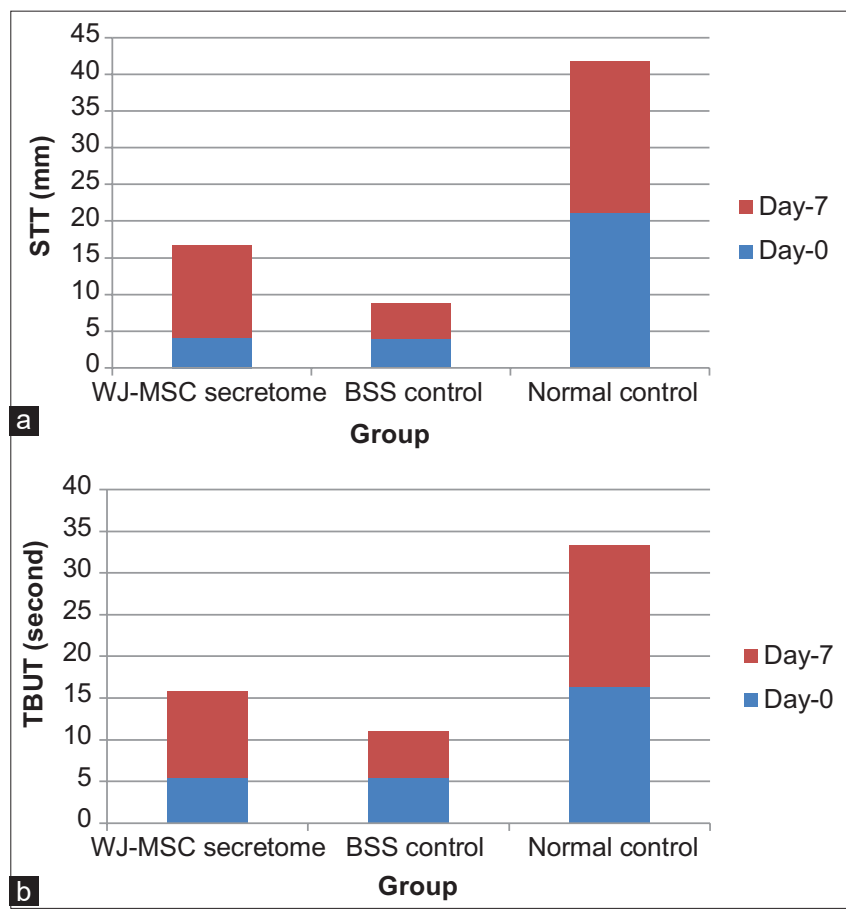

Figure 2: STT and TBUT score among groups. The graphs showed the changes of STT and TBUT score before and after treatment. WJ-MSC: Wharton's jelly mesenchymal stem cell, BSS: Balanced salt solution, STT: Schirmer tear test, TBUT: Tear break-up time
Topical instillation of $R V$ preconditioned WJ-MSC secretome restored goblet cell in the conjunctiva

HE staining of the conjunctiva showed that the number of goblet cells which are responsible for mucous tear production was markedly decreased in BSS control group (0.84 \pm 0.21 cells/visual field) (Figure 3 ). The conjunctival goblet cell count was significantly higher in the eyes with topical instillation of WJ-MSC secretome ( $2.4 \pm 0.8$ cells/visual field, $p=0.023$ ) compared to the BSS control group. However, the restoration of goblet cell populations was markedly different from the normal control group $(12.89 \pm 2.99$ cells/visual field, $p=0.002)$ (Figure 4 and Figure 5).

\section{Topical instillation of $R V$ preconditioned WJ-MSC secretome decreased infiltration of inflammatory cells in the ocular surface}

HE staining showed the highest infiltration of inflammatory cells, mainly neutrophil and lymphocytes in the BSS group $(406.88 \pm 117.09$ cells/visual field $)$. The treatment with topical instillation of WJ-MSC secretome $(144.40 \pm 56.92$ cells/visual field, $p=0.01)$ 
Table 2: Mean area of fluorescein dye staining in cornea

\begin{tabular}{lll}
\hline Treatment group & $\begin{array}{l}\text { Fluorescein dye staining } \\
\text { area Day-0 (Pixel) }\end{array}$ & $\begin{array}{l}\text { Fluorescein dye staining } \\
\text { area Day-7 (Pixel) }\end{array}$ \\
\hline BSS control & $7.92 \times 10^{5} \pm 3.67 \times 10^{4}$ & $1.2 \times 10^{6} \pm 8.51 \times 10^{4}$ \\
WJ-MSC secretome & $7.98 \times 10^{5} \pm 2.09 \times 10^{4}$ & $1.92 \times 10^{5} \pm 1.05 \times 10^{4 a}$ \\
\hline a $<0.05$ verss BSS control group 7 at 7 days after treatment (independent t-test). WJ-MSC: Wharton's jelly
\end{tabular}

${ }^{a} \mathrm{p}<0.05$ versus BSS control group at 7 days after treatment (independent t-test). WJ-MSC: Wharton's jelly mesenchymal stem cell, BSS: Balanced salt solution.

markedly decreased the infiltration of inflammatory cells compared to BSS control group, in which neutrophil was the predominance inflammatory cell. We found that inflammatory cell in WJ-MSC secretome group was 2.5 fold higher than the normal control group (58.88 \pm 20.01 cells/visual field, $p=0.055)$; however, it was not significant (Figure 5).

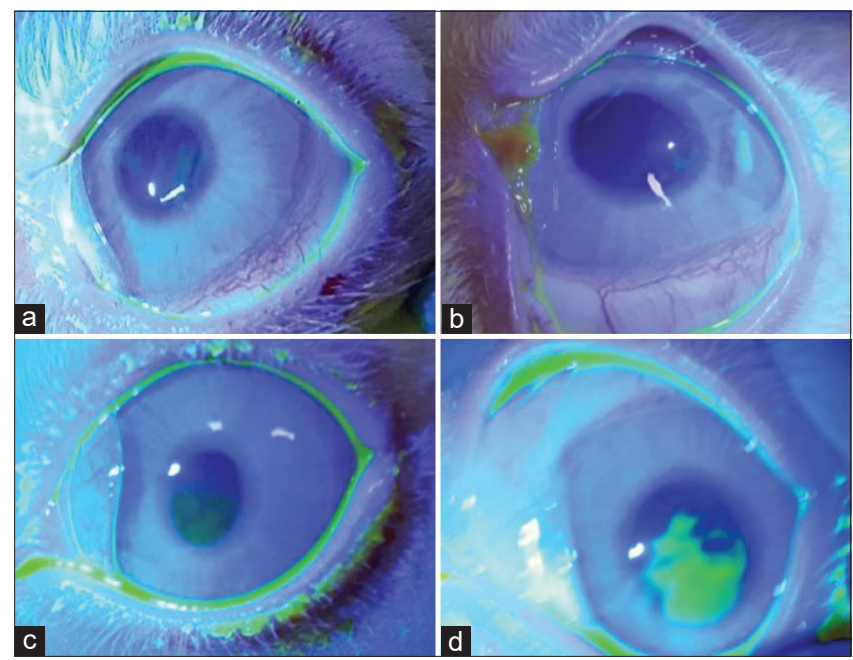

Figure 3: Topical instillation of RV preconditioned WJ-MSC secretome promoted corneal epithelial regeneration. Fluorescein dye staining in cornea at day-0: (a) WJ-MSC secretome group, (c) BSS control. Fluorescein dye staining in cornea at day-7: (b) WJ-MSC secretome group, (d) BSS control. WJ-MSC: Wharton's jelly mesenchymal stem cell, BSS: Balanced salt solution, Green staining: Fluorescein staining in corneal epithelial defect

\section{Topical instillation of $R V$ preconditioned WJ-MSC secretome reduced VEGF-A level in aqueous tear}

The level of VEGF-A in aqueous tear was relatively similar at baseline between WJ-MSC secretome group and BSS control group. Topical instillation WJ-MSC secretome significantly reduced VEGF level $(11.7 \pm 2.79 \mathrm{pg} / \mathrm{mL}, \mathrm{p}=0.003)$ in aqueous

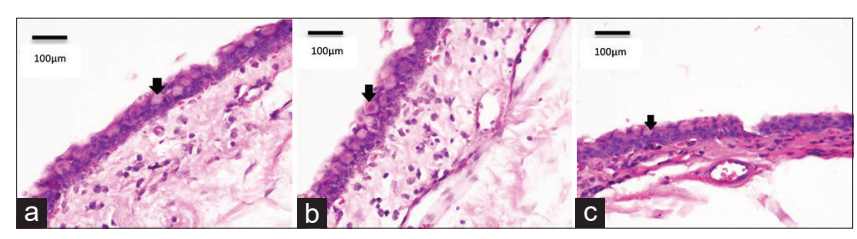

Figure 4: Topical instillation of RV preconditioned WJ-MSC secretome restored corneal goblet cell density (arrow: Goblet cell). (a) WJ-MSC secretome group, (b) normal control group, (c) BSS control group. WJ-MSC: Wharton's jelly mesenchymal stem cell, BSS: Balanced salt solution. (Hematoxylin-eosin staining, 400× magnification, light microscope, Nikon H600L with DS Fi2 300 megapixel camera). Black bar: $100 \mu \mathrm{m}$ tear compared to the BSS control group (55.55 \pm $13.3 \mathrm{pg} / \mathrm{mL}$ ) (Figure 5). However, the VEGF level still higher than the normal control group $(5.05 \pm 1.51 \mathrm{pg} / \mathrm{mL}$, $p=0.009$ ).

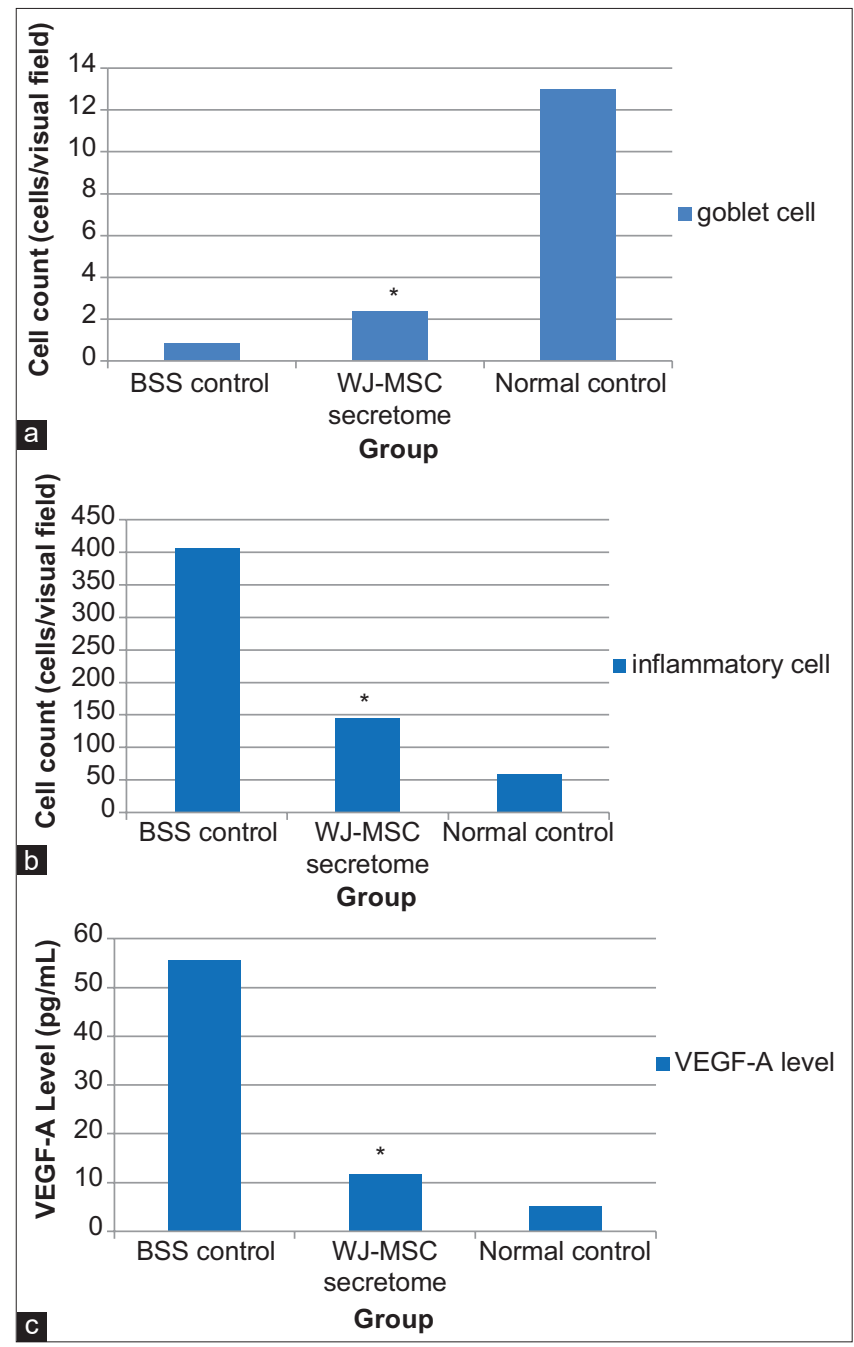

Figure 5: The effect of topical instillation of RV preconditioned WJ-MSC secretome on goblet cell, infiltration of inflammatory cell in ocular surface, and vascular endothelial growth factor (VEGF)-A leve in aqueous tear. (a) Goblet cell number, (b) inflammatory cell number, (c) VEGF-A level. WJ-MSC: Wharton's jelly mesenchymal stem cell, BSS: Balanced salt solution. * $p<0.05$ versus BSS control group

\section{Discussion}

To best of our knowledge, this is the first study conducted to develop the conditioned secretome using RV supplementation to decrease VEGF secretion. In this study, $0.1 \mu \mathrm{M}$ RV was successfully to promote the secretion of EGF and HGF, while decreases the level of VEGF. The previous study revealed that conditioned media from retinal pigment epithelial (RPE) cells treated with RV has the ability to inhibit human umbilical vein endothelial cells tube formation. RV at $50 \mu \mathrm{M}$ concentration suppressed VEGF secretion in hypoxic RPE cells through inhibition of CXC-chemokine 
receptor 4 [5], [6], [9], [10], [11]. This is the first study that investigated the therapeutic effect of the topical application of specifically manufactured stem cell secretome in severe DED model. Anumber of researches have already explored the effect of MSC secretome on corneal regeneration; however, this corneal defect was not co-exist with the presence of DED in which lacrimal gland dysfunction and inflammatory process are the main underlying pathologies [3], [9], [12], [13].

Our study revealed a significant improvement of tear production after topical instillation of RV preconditioned WJ-MSC secretome in the animal model of severe DED. The recovery of lacrimal gland function might be related to the immunomodulatory effect of the secreted product derived from WJ-MSC. However, the histological section of the lacrimal gland has yet to be evaluated in this study. Other study demonstrated that intraglandular transplantation of MSC reduced the infiltration of inflammatory cells in the intraorbital gland and ocular surface of the murine model of ConAinduced inflammatory dry eye. Other study reported a significantly increased tear production and goblet cell number through the immunomodulatory effect of MSC without long-term engraftment. Evidence of no long-term engraftment indicated that MSC exerts their therapeutic potential by their paracrine effect of cellsecreted factors [14], [15]. Single dose of allogeneic MSC transplantation in a dog with mild to moderate DED showed a significant increase in STT and ocular surface improvement in short- and long-term follow-up. However, an experimental study in a dog with severe DED revealed the improvement of STT and clinical sign without complete restoration of ocular surface status [16]. In another study, topical instillation of MSC in a week leads to an increase in aqueous tear volume and improvement in ocular surface evaluation tests in benzalkonium chloride-induced dry eye model in rats. The study reported that topical instillation of MSC might decrease inflammation, increase tear volume production and improve clinical appearance of the ocular surface [7].

We found an improvement of ocular surface inflammation after topical instillation of RV preconditioned WJ-MSC secretome. This clinical profile was in accordance with lower infiltration of inflammatory cells within conjunctiva and cornea that may describe the immunomodulatory effect of WJ-MSC secreted factors, mainly the anti-inflammation effect. The previous study stated that the innate and adaptive immune response is governed the immunomodulatory effect of MSC, through the secretion of different soluble substances in their secretome [17]. However, the exact immunomodulatory mechanism is yet to be elaborated [17], [18], [19], [20].

The chronic inflammatory condition of the ocular surface results in a gradual loss of conjunctival goblet cells [13], [14], [20]. Our study revealed that topical instillation of RV preconditioned WJ-MSC secretome successfully restored the goblet cell population compared to the control group. This result indicated a regenerative effect of WJ-MSC secretome on mucinproducing cells within conjunctival tissue, as shown with the improvement of TBUT. The anti-inflammatory effect of WJ-MSC secretome contributes to suppressing the chronic inflammatory process in the ocular surface, thus restores the goblet cell population and function. Moreover, MSC administered to a murine model of DED protected the ocular surface by suppressing CD4+ T-cell infiltration and decreasing levels of inflammatory cytokines such as IL-2 and IFN-Y [21], [22], [23], [24].

In severe DED, there is damage to the corneal surface [13], [14]. Topical instillations of RV preconditioned WJ-MSC secretome successfully promoted corneal epithelial regeneration in this study. It might be related to the high amount of EGF and HGF level contained in secretome derived from RV preconditioned WJ-MSC. EGF is a key factor for corneal epithelial regeneration, the crosstalk between EGF and HGF may facilitate epithelial regeneration by modulating the inflammatory response. Some studies showed the advancement of corneal wound healing after instillation of secretome derived from MSC. Its application may attenuate corneal inflammation by inhibiting the proinflammatory cytokines and infiltration of inflammatory cells [25], [26], [27]. The study described the effects of MSC secretome on ethanol induced-human corneal epithelial progenitor cells (hCEPs) injury, they found that MSC secretome enhanced survival, proliferation, and inhibited apoptosis of injured hCEPs [27]. A recent study reported significant improvement of corneal epithelial regeneration in the atropine-induced dry eye in rabbits after the administration of conditioned media derived from human uterine cervical epithelial stem cells (CM-hUCESC). Those studies showed that the corneal regenerative effect of stem cell conditioned media might be facilitated by decreasing corneal pro-inflammatory TNF- $\alpha$, MCP-1, MIP-1 $\alpha$, and IL-6 cytokines. In addition, secretome derived from hUCESC showed the regenerative and anti-apoptosis effect in corneal epithelial cells through a high level of metalloproteinase inhibitors TIMP-1 and TIMP-2 [27], [28].

Corneal neovascularization is the hallmark of disease severity in chronic inflammatory DED. The increasing of VEGF-A in aqueous tear plays a key role in this neovascularization. The level of VEGF-A in aqueous tear was found to be lower in RV preconditioned WJ-MSC secretome group compared to BSS control group. Moreover, we did not find any growth of new vessels in both of histological section and ocular surface. However, MSC has been shown to be good activators of angiogenesis and secretes VEGF as the most potent angiogenic factor [29], [30]. In this study, we successfully decreased VEGF-A secretion from WJ-MSC culture with supplementation of $0.1 \mu \mathrm{M}$ RV. Another study showed that intracameral injection of human amniotic (hAM)-MSC reduces 
corneal neovascularization, opacity, and stromal infiltration of inflammatory cells [30]. Therefore, the effect of WJ-MSC secretome on the inhibition of corneal neovascularization need a longer time of observation and further exploration.

As limitation, we did not determine the exact mechanism of topical instillation of RV preconditioned WJ-MSC secretome that may contribute in the preservation ocular surface in experimental model of severe DED. However, our study may suggest the new insight to produce specific MSC secretome with low pro-angiogenic factor by supplementation of culture media with $0.1 \mu \mathrm{M} \mathrm{RV}$.

\section{Conclusion}

In conclusion, the study has revealed that Topical instillation of RV preconditioned WJ-MSC secretome has great potential as cell-free based therapy to preserved ocular surface in experimental model of severe DED. The challenge for further animal and clinical trial is to establish MSC culture conditions to produce safe, tolerable, and effective MSC secretome in eye drops preparation.

\section{References}

1. Villatoro AJ, Fernández V, Claros S, Alcoholado C, Cifuentes M, Merayo-Lloves $\mathrm{J}$, et al. Regenerative therapies in dry eye disease: From growth factors to cell therapy. Int J Mol Sci. 2017;18(11):2264. https://doi.org/10.3390/ijms18112264 PMid:29143779

2. Villatoro AJ, Fernández V, Claros S, Rico-Llanos GA, Becerra J, Andrades JA. Use of adipose-derived mesenchymal stem cells in keratoconjunctivitis sicca in a canine model. Biomed Res Int. 2015;2015:527926. https://doi.org/10.1155/2015/527926 PMid:25802852

3. Baradaran-Rafii A, AsI NS, Ebrahimi M, Jabbehdari S, Bamdad S, Roshandel D, et al. The role of amniotic membrane extract eye drop (AMEED) in in vivo cultivation of limbal stem cells. Ocul Surf. 2017;16(1):146-53. https://doi.org/10.1016/j. jtos.2017.11.001

PMid:29104070

4. Dudok DV, Nagdee I, Cheung K, Liu H, Vedovelli L, Ghinelli E, et al. Effects of amniotic membrane extract on primary human corneal epithelial and limbal cells. Clin Exp Ophthalmol. 2015;43(5):443-8. https://doi.org/10.1111/ceo.12480 PMid:25495256

5. Seong H, Ryu J, Jeong JY, Chung IY, Han YS, Hwang SH, et al. Resveratrol suppresses vascular endothelial growth factor secretion via inhibition of CXC-chemokine receptor 4 expression in ARPE-19 cells. Mol Med Rep. 2015;12(1):1479-84. https:// doi.org/10.3892/mmr.2015.3518

PMid:25815440
6. Safaeinejad Z, Kazeminasab F, Kiani-Esfahani A, Ghaedi K, Nasr-Esfahani MH. Multi-effects of resveratrol on stem cell characteristics: Effective dose, time, cell culture conditions and cell type-specific responses of stem cells to resveratrol. Eur J Med Chem. 2018;155:651-7. https://doi.org/10.1016/j. ejmech.2018.06.037

PMid:29935438

7. Song JK, Lee K, Park HY, Hyon JY, Oh SW, Bae WK, et al. Efficacy of carboxymethylcellulose and hyaluronate in dry eye disease: A systematic review and meta-analysis. Korean J Fam Med. 2017;38(1):2-7. https://doi.org/10.4082/kjfm.2017.38.1.2 PMid:28197326

8. Aluri HS, Samizadeh M, Edman MC, Hawley DR, Armaos HL, Janga SR, et al. Delivery of bone marrow-derived mesenchymal stem cells improves tear production in a mouse model of Sjögren's syndrome. Stem Cells Int. 2017;2017:3134543. https://doi.org/10.1155/2017/3134543

PMid:28348600

9. Beyazyıldız E, Pınarlı FA, Beyazyıldız O, Hekimoğlu ER, Acar U, Demir MN. Efficacy of topical mesenchymal stem cell therapy in the treatment of experimental dry eye syndrome model. Stem Cells Int. 2014;2014:250230. https://doi. org/10.1155/2014/250230

PMid:25136370

10. Komaratih E, Rindiastuti $Y$, Wirohadidjojo YW, Rantam FA, Dinaryati A, Lestari NM, et al. The resveratrol increase of hepatocyte growth factor (HGF) and epidermal growth factor (EGF) levels in wharton's jelly mesenchymal stem cells (WJ-MSCs) secretome: Toward cell free therapy in dry eye disease (DED). Biochem Cell Arch. 2019;19(2):1-7. https://doi. org/10.1080/21691401.2020.1817057

11. Spees JL, Lee RH, Gregory CA. Mechanisms of mesenchymal stem/stromal cell function. Stem Cell Res Ther. 2016;7(1):125 https://doi.org/10.1186/s13287-016-0363-7

PMid:27581859

12. Sánchez-Abarca LI, Hernández-Galilea E, Lorenzo R, Herrero $C$, Velasco A, Carrancio S, et al. Human bone marrow stromal cells differentiate into corneal tissue and prevent ocular graft-versushost disease in mice. Cell Transplant. 2015;24(12):2423-33. https://doi.org/10.3727/096368915×687480 PMid:25695936

13. Stevenson W, Chauhan SK, Dana R. Dry eye disease: An immune-mediated ocular surface disorder. Arch Ophthalmol. 2012;130(1):90-100. https://doi.org/10.1001/ archophthalmol.2011.364

PMid:22232476

14. Bron AJ, De Paiva CS, Chauhan SK, Bonini S, Gabison EE, Jain S, et al. TFOS DEWS II pathophysiology report. Ocul Surf. 2017;15(3):438-510. https://doi.org/10.1016/j.jtos.2019.08.007 PMid:28736340

15. Lee MJ, Ko AY, Ko JH, Lee HJ, Kim MK, Wee WR, et al. Mesenchymal stem/stromal cells protect the ocular surface by suppressing inflammation in an experimental dry eye. Mol Ther. 2015;23(1):139-46. https://doi.org/10.1038/mt.2014.159 PMid:25152016

16. Bittencourt MK, Barros MA, Martins JF, Vasconcellos JP, Morais BP, Pompeia C, et al. Allogeneic mesenchymal stem cell transplantation in dogs with keratoconjunctivitis sicca. Cell Med. 2016;8(3):63-77. https://doi.org/10.3727/215517916x693366 PMid:28003932

17. Glenn JD, Whartenby KA. Mesenchymal stem cells: Emerging mechanisms of immunomodulation and therapy. World J Stem Cells. 2014;6(5):526-39. https://doi.org/10.4252/wjsc.v6.i5.526 PMid:25426250

18. Coulson-Thomas VJ, Coulson-Thomas YM, Gesteira TF, 
Kao WW. Extrinsic and intrinsic mechanisms by which mesenchymal stem cells suppress the immune system. Ocul Surf. 2016;14(2):121-34. https://doi.org/10.1016/j. jtos.2015.11.004

PMid:26804815

19. Su W, Wan Q, Huang J, Han L, Chen X, Chen G, et al. Culture medium from TNF- $\alpha$-stimulated mesenchymal stem cells attenuates allergic conjunctivitis through multiple antiallergic mechanisms. J Allergy Clin Immunol. 2015;136(2):423-32. https://doi.org/10.1016/j.jaci.2014.12.1926 PMid:25652765

20. Stapleton F, Alves M, Bunya VY, Jalbert I, Lekhanont K, Malet $F$, et al. TFOS DEWS II epidemiology report. Ocul Surf. 2017;15(3):334-65. https://doi.org/10.1016/j.jtos.2017.05.003 PMid:28736337

21. Wen L, Zhu M, Madigan MC, King NJ, Billson FA, McClellan K, et al. Immunomodulatory effects of bone marrow-derived mesenchymal stem cells on pro-inflammatory cytokine-stimulated human corneal epithelial cells. PLoS One. 2014;9(7):e101841. https://doi.org/10.1371/journal.pone.0101841 PMid:25003339

22. Murri MS, Moshirfar M, Birdsong OC, Ronquillo $Y$, Ding $Y$, Hoopes PC. Amniotic membrane extract and eye drops: A review of literature and clinical application. Clin Ophthalmol. 2018;12:1105-23. https://doi.org/10.2147/opth.s165553 PMid:29950805

23. Magaña-Guerrero FS, Domínguez-López A, MartínezAboytes P, Buentello-Volante B, Garfias Y. Human amniotic membrane mesenchymal stem cells inhibit neutrophil extracellular traps through TSG-6. Sci Rep. 2017;7(1):12426. https://doi.org/10.1038/s41598-017-10962-2 PMid:28963485

24. Javorkova E, Trosan P, Zajicova A, Krulova M, Hajkova M, Holan V. Modulation of the early inflammatory microenvironment in the alkali-burned eye by systemically administered interferony-treated mesenchymal stromal cells. Stem Cells Dev.
2014;23(20):2490-500. https://doi.org/10.1089/scd.2013.0568 PMid:24849741

25. Bermudez MA, Sendon-Lago J, Eiro N, Treviño M, Gonzalez F, Yebra-Pimentel E, et al. Corneal epithelial wound healing and bactericidal effect of conditioned medium from human uterine cervical stem cells. Invest Ophthalmol Vis Sci. 2015;56(2):98392. https://doi.org/10.1167/iovs.14-15859 PMid:25613942

26. Ljubimov AV, Saghizadeh M. Progress in corneal wound healing Prog Retin Eye Res. 2015;49:17-45. https://doi.org/10.1016/j. preteyeres.2015.07.002

PMid:26197361

27. Oh JY, Ko JH, Kim MK, Wee WR. Effects of mesenchymal stem/ stromal cells on cultures of corneal epithelial progenitor cells with ethanol injury. Invest Ophthalmol Vis Sci. 2014;55(11):7628-35. https://doi.org/10.1167/iovs.14-15424

PMid:25370509

28. Sendon-Lago J, Seoane S, Martinez-Ordonez A, Eiro N, Saa J, Vizoso FJ, et al. Corneal regeneration by conditioned medium of human uterine cervical stem cells is mediated by TIMP-1 and TIMP-2. Exp Eye Res. 2019;180:110-21. https://doi. org/10.1016/j.exer.2018.12.004

PMid:30557571

29. Anderson JD, Johansson HJ, Graham, CS, Vesterlund M, Pham MT, Bramlett CS, et al. Comprehensive proteomic analysis of mesenchymal stem cell exosomes reveals modulation of angiogenesis via nuclear factor-kappaB signaling. Stem Cells. 2016;34(3):601-13. https://doi.org/10.1002/stem.2298 PMid:26782178

30. Navas A, Magana-Guerrero FS, Dominguez-Lopez A, Chavez-Garcia C, Partido G, Graue-Hernandez EO, et al Anti-inflammatory and anti-fibrotic effects of human amniotic membrane mesenchymal stem cells and their potential in corneal repair. Stem Cells Transl Med. 2018;7(12):906-17. https://doi.org/10.1002/sctm.18-0042

PMid:30260581 